\title{
Using Ants, Animal Behavior \& the Learning Cycle to Investigate Scientific Processes
}

\author{
Author(s): Russell A. Ligon, Adam G. Dolezal, Michael R. Hicks, Michael W. Butler, Nathan I. \\ Morehouse, Tirupalavanam G. Ganesh
}

Source: The American Biology Teacher, 76(8):525-534.

Published By: National Association of Biology Teachers

URL: http://www.bioone.org/doi/full/10.1525/abt.2014.76.8.6

BioOne (www.bioone.org) is a nonprofit, online aggregation of core research in the biological, ecological, and environmental sciences. BioOne provides a sustainable online platform for over 170 journals and books published by nonprofit societies, associations, museums, institutions, and presses.

Your use of this PDF, the BioOne Web site, and all posted and associated content indicates your acceptance of BioOne's Terms of Use, available at www.bioone.org/page/terms_of_use.

Usage of BioOne content is strictly limited to personal, educational, and non-commercial use. Commercial inquiries or rights and permissions requests should be directed to the individual publisher as copyright holder. 


\section{INQUIRY \&}

\section{Using Ants, Animal Behavior \& the Learning Cycle to Investigate Scientific Processes}

- RUSSEll a. LIGON, ADAM G. DOLEZAL, MICHAEL R. HICKS, MICHAEL W. BUTLER, NATHAN I. MOREHOUSE, TIRUPALAVANAM G. GANESH

\begin{abstract}
The behavior of animals is an intrinsically fascinating topic for students from a wide array of backgrounds. We describe a learning experience using animal behavior that we created for middle school students as part of a graduate-student outreach program, Graduate Partners in Science Education, at Arizona State University in collaboration with a K-8 public school. This activity capitalizes on the interest that animal behavior can generate to introduce and reinforce student understanding of the scientific method. Specifically, our activity highlights the general utility of the scientific method and uses this method to examine ant social behavior, with emphasis on generating and testing hypotheses. Furthermore, this activity introduces the idea of animal societies and encourages students to apply the concepts they learn to other species, including humans. By collecting ants locally, from schoolyards or nearby habitats, this experience situates learning in the context of students' own communities. We also provide optional assessment materials that teachers can use to assess learning objectives and standard mastery.
\end{abstract}

Key Words: Ethology; scientific method; hypothesis; data collection; NGSS; middle school.

As part of a long-term outreach program at Arizona State University, the Graduate Partners in Science Education program has brought enthusiastic graduate students from the life sciences to work with middle school children and teachers in inner-city urban settings to create engaging learning experiences. Here, we describe antbased instructional activities that we designed to teach and reinforce the scientific process, using animal behavior to capture the attention and interest of students. Investigating animal behavior can provide a remarkably effective way to engage middle school students in life science topics and reinforce the scientific method in the context of doing science. Unfortunately, it is not usually possible for teachers to bring

Investigating animal
behavior can provide a
remarkably effective way
to engage middle school
students in life science
topics.

in terrariums, allowing learners to frequently observe and interact with the animals under study. This learning unit can be adapted to meet the needs of educators and their classrooms, regardless of direct access to native ant species in the school or local community.

This learning unit was specifically designed to help students develop their observational and deductive skills, both within and outside of the context of scientific inquiry. Additionally, we hoped that following this lesson, students would be able to apply these observational skills when examining other social animals - even humans. We also encouraged students to consider the field of animal behavior as a potential career option. Our experience suggests that this unit can be highly effective in engaging student interest and eliciting critical thinking related to the scientific process.

\section{Background Knowledge}

Behavioral ecologists study animal behaviors to gain a better understanding of the way the natural world works. From wolves hunting in packs (Post et al., 1999) to bees communicating with elaborate dances (Gould, 1975) to peacocks showing off their tail feathers to attract mates (Petrie \& Halliday, 1994), animals perform interesting, impressive, and exciting behaviors. This section is designed to introduce some of the fascinating insights that humans have learned from behavioral ecologists over the past century and use these insights as a jumping-off point for the remainder of this animal-behavior-driven lesson.

Before implementing this unit, teachers should familiarize themselves with several important concepts about animal behavior. First, it is important to understand that there are many ways to survive and thrive in the world, and natural selection has produced a great deal obviously charismatic animals like bear cubs and baby birds into the classroom. However, we offer an economical experience that relies on native ant species that can be brought into the classroom and housed of variation in morphology and physiology among different species, even those occupying similar niches. For example, birds and bats that fly and eat insects have drastically different body plans. So it is with

The American Bioloģy Teacher, Vol. 76, No. 8, pages 525-534. ISSN 0002-7685, electronic ISSN 1938-4211. (C2014 by National Association of Bioloģy Teachers. All rights reserved. Request permission to photocopy or reproduce article content at the University of California Press's Rights and Permissions Web site at www.ucpressjournals.com/reprintinfo.asp. DOI: $10.1525 / a b t .2014 .76 .8 .6$ 
Table 1. Learning objectives and Next Generation Science Standards (NGSS).

Learning Objectives

By the end of this activity, students will be able to

- Design and execute a scientifically valid experiment on animal behavior using replicates and quantifiable observations.

- Articulate what an adaptation means in a biological context.

- Apply lessons of experimental design to a novel behavioral system (e.g., pride formation in lions).

- Compare behaviors in different species with regard to the social context as well as their functions.

\section{NGSS Crosscutting Concepts}

This lesson emphasizes the idea that objects and events in natural systems occur in consistent patterns, and that these patterns can be better understood through measurement and observation (MS-LS4-1; MS-LS4-2). Furthermore, this lesson highlights the idea that cause-and-effect relationships can be useful in predicting natural events and phenomena (MS-LS3-2).

\section{NGSS Disciplinary Core Ideas}

This lesson addresses key topics of animal behavior, growth, and development (LS1.B), the interdependency of organisms and ecosystems (LS2.A), and the integral idea of adaptation (LS4.C) by natural selection (LS4.B). Specifically, this lesson introduces key ideas regarding how organisms interact and engage in group behavior, as well as how these social behaviors relate to survival and adaptation. Additionally, this lesson emphasizes the mechanisms by which individuals recognize group vs. non group members (LS2.D).

\section{NGSS Science Practices}

This lesson addresses key scientific practices by allowing students to analyze and interpret data that they themselves collect, in order to make sense of collective, cooperative, and antagonistic social behavior using logic and reason (MS-LS4-1). Additionally, this lesson allows students to apply scientific ideas to real-world observations in an attempt to generate explanations for these observations (MS-LS4-2). Lastly, this lesson facilitates the construction of qualitative and quantitative explanations for observed relationships between variables (MS-LS4-4).

behavior. Some animals feed on abundant food sources that need not be monopolized and, consequently, show very little aggression toward other members of their species. Other animals rely on finite resources and must fight aggressively to defend these resources from other animals, including conspecifics. Second, the behaviors that animals exhibit are just as important as their physical bodies. Both are adaptive and help the animal survive. It is critically important for students to realize that traits that help animals survive or reproduce (i.e., adaptations) can include the behaviors they perform. Third, animals behave in different ways depending on both internal and external factors. A hungry shark is going to swim faster to catch a fish, a sick lion is going to conserve energy by resting, and a mockingbird in the middle of the breeding season is going to spend more time singing. Animal behaviors are also sensitive to external factors such as time of day, climate, and predation risk. For example, an owl will not hunt actively during the day, a toad will wait for rain before serenading his future mates, and a field mouse will stop its search for food if a fox is nearby. How these internal and external factors influence an individual's behavior varies between members of a given species and among different species. Fourth, animals perform some behaviors naturally without ever having to learn them (e.g., baby birds begging for food, joey kangaroos crawling to their mother's pouch, and salmon fry swimming downstream after hatching), and others only after honing them through practice or by learning them from other members of their species (e.g., social play in lion cubs, chameleons learning to avoid distasteful insects, and facial-gesture imitation in young humans). Lastly, teachers should have a basic understanding of the biology of ants, the most abundant multicellular animals on the planet (Hölldobler \& Wilson, 2009).

Ants, like honey bees, are eusocial organisms. These animals live in large associations of related individuals that cooperate to achieve collective success. Eusocial insects are those that meet three major criteria. First, there is a reproductive division of labor: the majority of the colony is made up of workers that do not mate or reproduce, and all the reproduction is performed by a queen (or a small number of queens). Second, there is cooperative care of young: sterile workers cooperate to care for the eggs and larvae in a colony, even though they did not produce those offspring themselves. Third, there is an overlap in generations: parents and offspring share the nest together, producing several generations of new offspring together.

Because the queen produces all the offspring, the individuals in an ant colony are highly related. In fact, the worker ants in any colony are usually sisters, sharing the queen as a mother. Therefore, it is beneficial for them to cooperate; even though the workers are not raising their own offspring, they are caring for their sisters. Thus, it is possible to think of an ant colony as a large family that cooperates to raise the offspring of one shared mother. Because all the ants in a colony are working together as a family group, they are competing against other, unrelated colonies, even within the same species. Other colonies live in the same environment and are seeking food and other shared resources. Therefore, workers have to express behaviors to protect their own colony. One way this is achieved is through the ability to identify other ants as being members of the colony or not. This is primarily accomplished through the ants' sense of smell; each colony has a slightly different odor, and individual ants express this odor. When ants interact, they use their antennae to smell each other. If the ants are from the same colony, they will have the same odor, sense this, and cooperate. However, if the odors are different, the ants will respond appropriately, usually with aggressive action. This allows ant colonies to operate as a cohesive group while still protecting themselves against outsider ants. 
Other than their interesting biology and behavior, there are numerous benefits of working with locally abundant insects in the classroom. Specimens are usually free, are easy to acquire, and include a certain amount of flexibility compared to working with vertebrate animals, a process that generally requires specific permits. Ants, in particular, are ideal organisms for classroom studies of animal behavior because ant colonies exhibit a wide array of interesting behaviors and are easily maintained in captivity (see Appendix 1: How to Care for Ants). Their large numbers also allow students to create and test novel hypotheses, as well as repeat important components of their behavioral studies. As eusocial insects, ants are also highly territorial and will defend their colony from intruders. Therefore, with a few ant colonies, students can experiment with social behavior in ants from the same colonies and compare how these interactions differ from those between ants from different colonies. Students can then be challenged to apply their observations of social behavior in ants to the principles that govern the social behavior of other animals such as wolves and humans.

\section{$\bigcirc$ Learning Units}

The high-level learning goal for this unit is to investigate social behavior in native ant species. The session starts by eliciting students' prior knowledge from their own life experiences, getting them involved by asking them to share about animal social behaviors they have noticed or learned about. Using the provided background knowledge (see Supplementary Animal Behavior slideshow; http://gpse.asu .edu/gpse.asu.edu/Supplement.html), students then develop testable hypotheses regarding how ants might respond to ant intruders from other groups. Students are then posed with the challenge of forming hypotheses and designing experiments to test those hypotheses in the context of ant social behavior. Throughout, we have used a popular instructional planning method, the learning cycle (Colburn \& Clough, 1997), to organize the learning experience.

\section{Engage}

A brief ( $\sim 7$ minute) presentation about some of the behaviors that animals exhibit will be useful to engage learners (see Supplementary Animal Behavior slideshow). Teachers should address behaviors that are universal, such as eating, reproduction, movement, and so on, and may also elect to offer a few examples that they are personally enthusiastic about or to elicit students' prior knowledge on the topic. At this stage, it is important to introduce the idea of social behavior using wolf packs, lion prides, bees, ants, and humans to illustrate the diversity of social behaviors exhibited by different animals.

After talking about behavior, introduce and discuss some of the ways that scientists study animal behavior using the scientific method (see Supplementary Scientific Method; http://gpse.asu.edu/gpse.asu .edu/Supplement.html) to answer questions about how animals behave and adapt to their environments. This is a perfect opportunity to expand and elaborate on how the scientific method can be used to answer a wide range of questions to better understand our world. Describe the concept of a research question, what a hypothesis is (and is not), how predictions are made, how experiments are constructed to test predictions, how data are collected, and how data are analyzed to provide support for, or against, the hypothesis in question. With the importance of the scientific method on their minds, students will be primed to begin focused observations on real-life animals, the ants from their own backyards!

At this point, teachers can introduce ants as the main topic of the lesson and encourage students to think about the general kinds of behaviors that ants are likely to perform. Ask open-ended questions (e.g., How do ants get food? How do they get it back to their home? How do ants protect themselves from predators?) to get each student involved in the process, and have students write down their answers in lab notebooks before opening up the questions to verbal input from all students. Guide student responses toward discussing the overarching idea of ant social behaviors. From discussion of social animals, students should also generate hypotheses regarding whether ants can recognize one another.

Whether in wolves, bees, humans, or ants, when uninvited strangers from the same or different species enter the home turf of the organism, the resident often responds with some form of aggression to protect food, space, or offspring. In their science notebooks, students can contrast (1) how they would feel if a stranger entered their house uninvited and approached them and (2) how they would feel if a stranger came within a few feet of them when they were in a communal setting, like a mall or grocery store. Then ask students if they think animals like ants will react in a similar way. How will ant reactions be different? You will likely find that students' predictions about how a group of ants will treat ants from different colonies include some aspect of aggression. This is a perfect opportunity to guide student discussions toward the idea of how to measure the different kinds of behaviors the ants will likely show. Pictorial guides of common ant behaviors can be useful in helping students objectively score the behavior of ants (Figure 1).

\section{No notice $=0 \quad$ Contact $=1 \quad$ Antenna fighting $=2 \quad$ Biting $=3 \quad$ Heavy fighting $=4$}
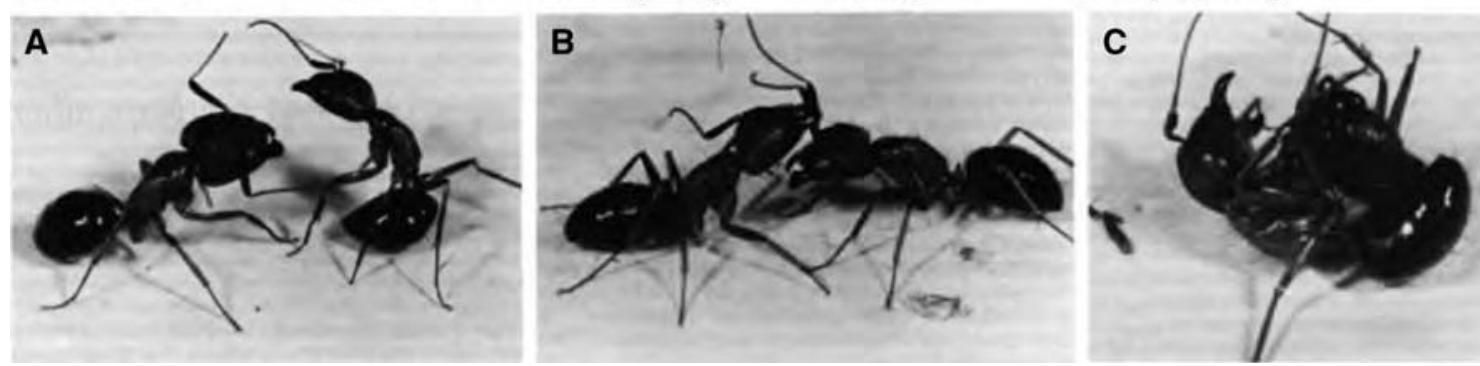

Figure 1. Representative images of aggressive ant behavior, including (A) antenna fighting, (B) biting, and (C) heavy fighting. "No notice" and "Contact" can include ants remaining on the opposite side of the dish, or ants in contact with each other but non-intrusively (not shown). Photographs from Hölldobler and Wilson (2009), used with permission. 


\section{Explore}

\section{Activity 1: Collecting and observing local ants in their natural environment}

This activity using ants will need to be tailored to the local environment, because the ant species and availability will be highly variable. If local ants are to be used, begin well in advance by leading a discussion with students and asking where they have observed ants locally. Use this time to evaluate and add to their background knowledge of basic ant information. It can be useful to talk about the variety of habitats that ants live in (e.g., in holes in the ground, inside or under logs, in trees) and the variety of foods that they eat (e.g., seeds and other insects). While it is likely to come up, teachers should downplay ants as pests in the home, and discuss their ecological importance and variety instead.

Many areas in the western United States have locally available harvester ants, such as those used in ant farms. These ants are large, live in conspicuous nests in the ground, and are often a familiar sight to students, even in very urban areas. The only drawback to these ants is that care must be taken, because they possess a very painful sting (wear gloves!). In the midwestern and eastern United States, large carpenter or wood ants are similarly conspicuous. However, since they live in and under fallen logs, they may be more difficult to collect - although, unlike harvester ants, these ants do not sting. Fire ants, however, should not be used, because they bite and sting, and care should be taken to avoid contact with these species (see link for help in identifying fire ants). If no local ants are accessible, ants can be acquired inexpensively online from ant-farm suppliers and should work relatively well. However, it is important to note that ants purchased through suppliers should not be released into the environment at the end of the activity, because they have originated from a different geographic area and could be damaging to the locally established ant communities.

Once the discussion of ant observation unfolds, the instructor and students may attempt to collect ants from a natural or seminatural setting. Detailed, step-by-step instructions for this activity can be found in Appendix 2. Even if ant-farm ants are to be used in the subsequent activity, it is useful and interesting to have the students make basic observations of ant behavior. Have students describe the ants' nest, how they forage, and so on. If ants are found locally, it can be interesting to compare observations in their natural setting to those made in captivity. Try to find two different species of ants and two colonies of each species. If this is not possible, two colonies of one species will suffice for most of the procedures. In addition to collecting ants for Activity 2, the species collected can also contribute to the citizen science project "School of Ants," wherein individuals or classes send locally captured ants to scientific labs for identification and inclusion in a country-wide dataset (http://schoolofants.org). Lastly, make sure to follow the guidelines in Appendix 1 to keep ants alive and well during their stay in the classroom.

\section{Activity 2: Investigating behavioral responses to intruders}

Begin by asking students to formulate and record hypotheses, based on their initial observations of ants and background knowledge of social animals, regarding how members of the same ant colonies will interact with (1) ants from their own colony, (2) ants of the same species but from a different colony, and (3) ants of a different species and from a different colony. Discuss the importance of the ants' ability to recognize nest mates and non-nest mates. Specifically, engage the students in a discussion about how recognition might occur and how the ability to recognize one another might affect the ants' ability to acquire food, water, and space. What might happen if an intruder ant appeared? Why would these responses to intruders be beneficial?

Before your students begin to study the social behaviors of ants, reiterate information about the specific ants under study. This information should include where the ants were collected, their habitat types, and the density of the ants (which can be estimated for the two different species on the basis of your observations in the field). Next, split students into groups, asking each group member how they might design an experiment to test their hypotheses. Explain the need to replicate experiments for statistical analysis. After allowing group members to discuss their individual hypotheses, each group should decide on a single hypothesis to focus on, based on the feasibility of the proposed methods, the ability to replicate the proposed experiments, and the overall group interest in the specific idea being tested. Once students have decided on a hypothesis to test, they should construct behavioral scoring sheets (see Appendix 4) to use during ant interactions. These behavioral scoring sheets should allow students to quantify the relative frequencies of the different behaviors that they deem most relevant to answering their own particular research question. Additionally, we have provided step-by-step instructions for conducting social-interaction experiments with the ants in Appendix 3. Feel free to modify the specific details regarding experimental design to fit student hypotheses.

If students need help getting started with ideas regarding how to test their hypotheses, some potential experimental designs are illustrated in Figure 2. Other experiments might include (1) using

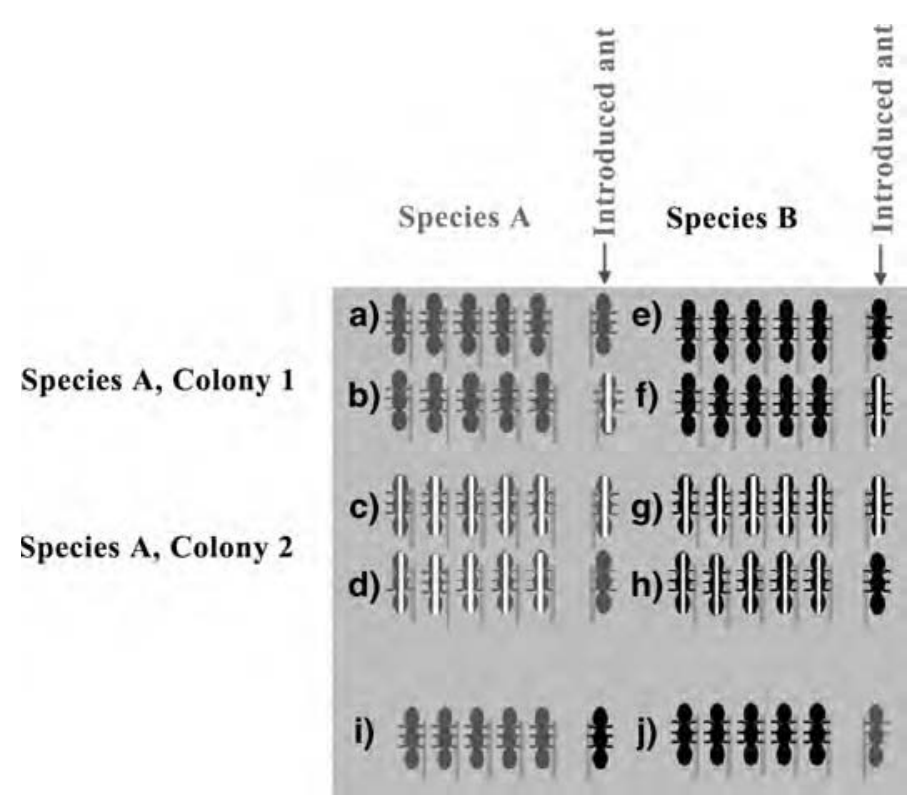

Figure 2. Graphic representation of possible interactions (a-j) tested in Appendix 3. All iterations should be repeated 3-5 times. Gray and black ants denote separate species, and stripes indicate ants of the same species but of a different colony. Note: If only one ant species is available, only a-d can be performed. If experiment time is constrained, instruct half of the groups to perform a-d and $i$, and instruct the other half of the groups to perform e-h and j. Students can then share data during the assessment section of the experiment. 


\section{Table 2. Sample evaluation questions.}

\begin{tabular}{|l|}
\hline Question \\
\hline 1. What is an adaptation? Can a \\
behavior be an adaptation? \\
Give an example of a \\
behavioral adaptation.
\end{tabular}

\section{Response}

This question address NGSS Disciplinary Core Ideas LS1.B, LS2.A, LS4.B and LS4.C. Adaptation is a core concept in modern biology, but many students may struggle to define it. Contemporary biologists define adaptations as traits that confer higher fitness to their bearers than any other alternative trait states that exist in their population. This context-dependent definition is critical. An adaptation is something that does better than existing alternatives and is therefore maintained or promoted in the population by natural selection. Alternatives that do not currently exist are not relevant, because they cannot "win" or "lose" in competition. After making sure that students understand this concept, the instructor should ask whether behaviors can be adaptations. This involves asking whether individuals can differ in behavior from each other such that some behaviors may confer higher fitness than others. In fact, consistent individual differences in behavior (often called "animal personalities" or "behavioral syndromes") are a major area of research right now in behavioral ecology. Do animals or humans show differences in their level of aggression, for example? Appealing to students to offer animal or human examples of behavioral adaptations should help students think more clearly about these concepts.

2. List three internal and three external factors that can influence a behavior.

This question address NGSS Disciplinary Core Ideas LS1.B, LS2.A, LS4.B and LS4.C. Although the students may need no prompts to begin exploring this topic, the instructor may choose to start with familiar internal and external influences such as hunger state or external temperature to get students thinking about how these types of influences differ from each other. Once students have considered basic relationships between behavior and other factors ("how" questions), the instructor should push students to consider why such behavioral responses exist. Why do these behavioral responses help animals? Are there any internal or external factors that do not influence behavior, and why? Students should understand and be able to communicate the adaptive value of behavioral flexibility and responsiveness.

3. Give two examples of ways that humans communicate without language. When do humans communicate without language? Give three examples of ways that animals communicate. Why do different animals communicate in different ways?

4. Humans do not have as strong a sense of smell as ants, so how do humans tell friend from foe or relative from nonrelative?

5. How do humans differ from ants with respect to how they treat strangers (i.e., someone they recognize as being on a different team/from a different place/unrelated)? Are there any ways that ants and humans treat strangers the same way?

6. Develop a hypothesis for why lions live in groups and describe an experiment you could design to test your hypothesis.
This question addresses NGSS Disciplinary Core Ideas LS1.B and LS2.A, as well as NGSS Crosscutting Concept MS-LS3-2. Students should be encouraged to draw from their own experiences in communicating without language to answer this question. Ideally, students will realize that particular factors favor the use of facial expressions or hand signals (like a need to be quiet) and that these cause-and-effect relationships are likely to work at a larger scale. For example, animals may be more likely to communicate with sound if they are nocturnal, more likely to communicate with visual signals if they have good vision and are active during the daytime, etc.

This question addresses NGSS Disciplinary Core Idea LS2.D. Instructors can have students discuss this question in small groups, allowing students to generate comprehensive lists of the ways that they can tell other humans apart. This discussion, as well as the lists generated, should be helpful in emphasizing the diversity of means by which a single species (humans) can tell one another apart, even if many of these methods have something in common (such as visual cues).

This question addresses NGSS Disciplinary Core Ideas LS2.D. We recommend a group discussion. The instructor should try to ensure that the students understand that there are a diversity of behaviors that both humans and ants use to interact with strangers (e.g., ignoring, making quick contact and then moving on, taking the time to become familiar with an individual, attacking, etc.). Once these points are established, leading the students to question the function of each of these behaviors will allow students to discuss issues such as what it means to be a stranger and, conversely, part of a group, and how group membership and dynamics can change with time. Some of these points may be first made with humans, but by asking probing questions (e.g., "What happens as new ants are born into the colony?") will help students to apply these concepts to nonhuman species.

This question addresses NGSS Science Practices MS-LS4-2. While multiple answers are acceptable, the instructor should make sure that the experiment will rely on data that can be collected with either observation or experimentation and that these data will allow the student to more comprehensively describe why lions live in groups, or predict scenarios under which lions may live in larger/smaller groups. 
one ant from two separate colonies to test whether ants in a "pack" act differently than ants alone, (2) using several ants from two separate colonies to test the behavior of two packs, (3) adding a resource such as honey or sugary cereal to the Petri dish to test whether this resource changes ant groups' behavior, (4) using soil from a neighboring ant colony to mask the foreign ant's smell, or (5) removing the acclimation time of the Petri dish so that both ants are "foreign."

\section{Expand}

Once students have conducted the actual ant experiments, with the replication required for a scientific approach, each student group should create a presentation of their animal behavior experiment. Students should include an introduction describing what they did and why, which will allow them to think critically about their own experimental process. We suggest that students elaborate on each part of the scientific process (observation, hypothesis, experiment, data analyses, interpretation) and be encouraged to focus on their own hypotheses. The special attention paid to hypotheses can reinforce the fact that hypothesis-driven research is an essential part of the scientific process. Students should be encouraged to make drawings to describe their experimental procedures, making special note of any modifications made during the experiment. Graphs representing their experimental data in the results section will allow for data-based inferences and analytical comparisons among student groups. We suggest graphs that represent the proportion of different behaviors observed in different experimental conditions, allowing for more straightforward comparisons across different treatments. Additionally, students should be asked to interpret what their data actually mean and record their inferences in their notebooks. Do the data support the students' hypotheses about group behavior? Do the data fail to support their hypotheses? Ask students to draw conclusions from their results and to briefly discuss what they have learned. The interpretation of the actual data that students have collected is essential to developing scientific reasoning.

\section{Evaluate}

To evaluate how well the students were able to understand and incorporate the scientific method to address their hypotheses, students should answer discussion questions individually. The questions can come from the teacher, from Appendix 4, or the students can generate (and answer) their own or one another's discussion questions (each experiment is unique). However, one of the overarching questions that should be answered is "What conclusions can be drawn from the experiment on the basis of the data you collected?" Allowing students to briefly present their experiment in front of the class (described above) will grant them an opportunity to showcase their learning, as well as encourage oral communication, argumentation, and scientific reasoning.
In addition to thinking about questions concerning their experiments and the data they collected, instructors can also evaluate the effectiveness of the activity with respect to larger learning goals using free response to the questions below. Instructors are encouraged to include additional questions that are specific to the experiences of their students during these activities, or that will assist the instructor in evaluating the students with respect to upcoming instructional goals or projects (Table 2 ).

\section{Ethical Treatment of Animals}

All the procedures presented here should be conducted thoughtfully and humanely to minimize any potential harm or discomfort to the ants. Ant colonies should be housed with care, and ants being used in experiments should only be kept in experimental arenas for the time required to test student hypotheses. Teachers should discuss respect for, and ethical treatment of, research animals prior to student exposure to the animals in this lab.

\section{References}

Colburn, A. \& Clough, M.P. (1997). Implementing the learning cycle. Science Teacher, 64(5), 30-33.

Gould, J.L. (1975). Honey bee recruitment: the dance-language controversy. Science, 189, 685-693.

Hölldobler, B. \& Wilson, E.O. (2009). The Superorganism: The Beauty, Elegance, and Strangeness of Insect Societies (pp. 285-286). New York, NY: Norton.

Petrie, M. \& Halliday, T. (1994). Experimental and natural changes in the peacock's (Pavo cristatus) train can affect mating success. Behavioral Ecology \& Sociobiology, 35, 213-217.

Post, E., Peterson, R.O., Stenseth, N.C. \& McLaren, B.E. (1999). Ecosystem consequences of wolf behavioural response to climate. Nature, 401, 905-907.

\begin{abstract}
RUSSELL A. LIGON (russell.ligon@gmail.com) and MICHAEL R. HICKS (mrhicks1@asu.edu) are at the School of Life Sciences, Arizona State University, 427 East Tyler Mall, Room 229W, Tempe, AZ 85287-4501. ADAM G. DOLEZAL (adolezal@iastate.edu) is in the Department of Ecology, Evolution, and Orģanismal Bioloģy, lowa State University, 353B Bessey Hall, Ames, IA 50011. MICHAEL W. BUTLER (butlermw@lafayette.edu) is in the Department of Biology, Lafayette College, 213 Kunkel Hall, Easton, PA 18042-1778. NATHAN I. MOREHOUSE (nim@pitt.edu) is in the Department of Biological Sciences, University of Pittsburgh, 223 Clapp Hall, Fifth and Ruskin Avenues, Pittsburgh, PA 15260. TIRUPALAVANAM G. GANESH (tganesh@asu.edu) is at the Ira A. Fulton Schools of Enģineering, Arizona State University, ECG 113, 501 E. Tyler Mall, Tempe, AZ 85287-5506.
\end{abstract}

(Appendix follows on the next page.) 


\section{Appendix 1: How to care for ants}

Where do I keep my ants? How do I keep them from getting loose?

Some species of ants are very good at climbing walls, and thus escaping. To avoid this, ants can be kept in closed Tupperware containers with air holes. Air holes can be created by poking many holes with a pin or needle or by cutting out a larger area from the lid and gluing fine mesh screen over the hole.

Many ants can be prevented from climbing up the walls of plastic or glass by coating the walls in a fine film of oil; using cooking oil spray, spray a small amount of oil on the walls or into a paper towel, and then spread the oil on the walls of the ant enclosure. Replenish as necessary. If ant escapes are of serious concern, place the containers inside a larger rubber tub with similar treatment, or place the enclosure on a table with the legs submerged in water-filled containers.

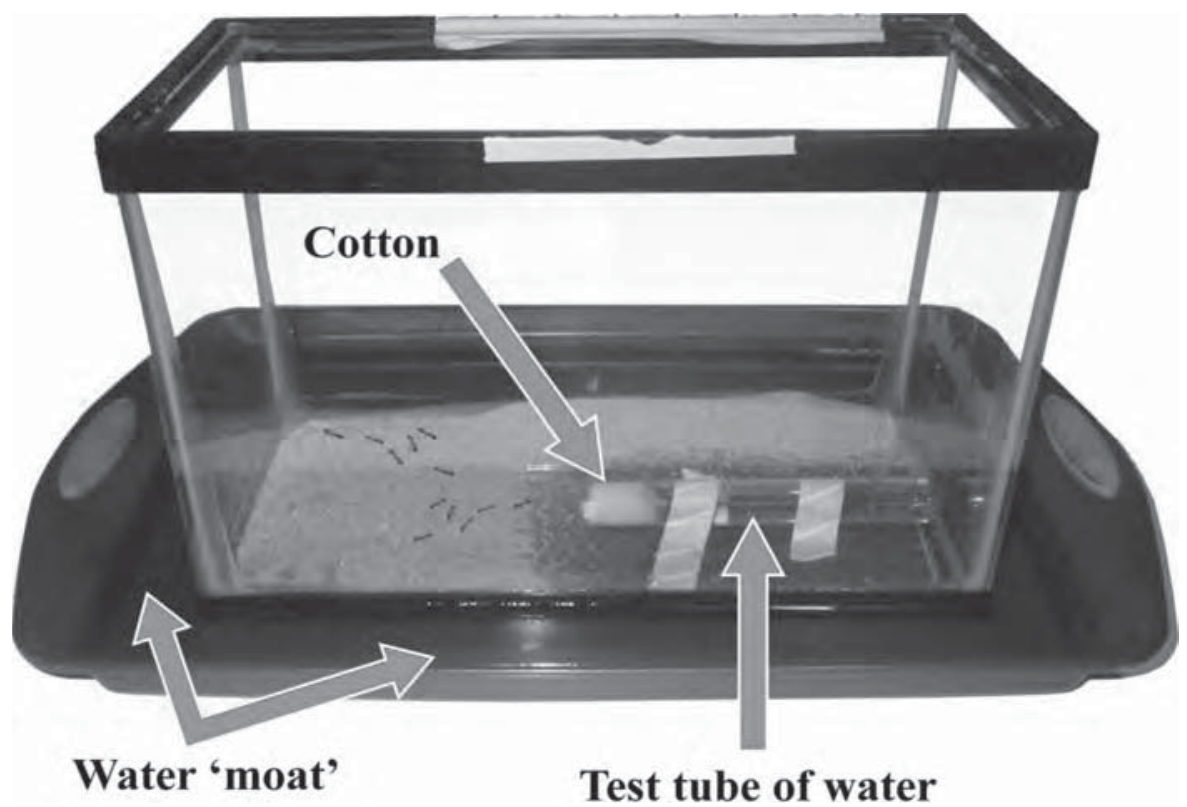

What do I feed my ants? How do I keep them alive?

The most important resource for keeping the ants alive is water. Test tubes or similar sized containers can be filled with water, and then a cotton ball inserted into the tube until the entire ball is wet; this allows the ants to access water without drowning. Tape the tubes to the bottom of the enclosure to prevent them from rolling around.

To feed the ants, tubes filled with sugar water can also be introduced. If no test tubes are available, wet cotton balls can be kept in the ant enclosure, but the water must be replenished as necessary. For food, ants can be fed a drop of honey, which will need to be replenished when it is eaten or crystallizes.

\section{Other resources}

Exact care for the ants will be somewhat dependent upon their species; there are many online resources for ant enthusiasts that can provide very specific information for the best levels of ant care. Some good sites include:

AntFarm: http://antfarm.yuku.com/

Ant Hill World: http://queenant.proboards.com/ 


\section{Appendix 2: Collecting and observing local ants in their natural environment}

\section{Materials (per group, 3-4 students suggested)}

$\begin{array}{lll}\text { Collecting and housing containers } & \text { Science Notebook/pen } & \text { Hand lens/ magnifying glass } \\ \text { Gloves (e.g., latex or nitrile) } & \text { Masking tape } & \text { Camera }\end{array}$

Insect aspirator (optional, though very useful) can be obtained inexpensively from BioQuip

http://www.bioquip.com/search/DispProduct.asp?pid=1135

Ants (2 ant species, 2 colonies per species $=4$ total colonies)

- If local ants will be used, teachers will need a shovel/trowel and tweezers/forceps

- If ants will be purchased online, no collection-specific materials are required

\section{Group Members}

- Recorder

- Observer

- Ant handler(s)

- Manager

\section{Procedure}

1. Plan a trip with the class to walk the school grounds or to go to a local park that contains an ant colony of interest. Ask students to dress appropriately, e.g. close-toed shoes.

2. Perform observations with minimal disturbance of colony. Ask students to record their observations in their science notebook. Each student should make at least three observations.

3. Use shovel or trowel to dig into ground-nesting ant colonies, or to dig into the wood of those nesting in logs. It may be desirable to wear gloves; beware, however, since many ants can (though with some difficulty), sting through gloves.

4. Use forceps and/or aspirator to collect ants into labeled containers. Make sure to keep colonies separate. Collect as many ants as necessary, preferably 30-50 from each colony.

5. To house the ants, keep them in the plastic containers. To prevent the ants from escaping, keep lids on them. Before opening containers, gently shake the ants around so that they fall to the bottom.

6. The most important factor for keeping the ants alive is moisture. Simply placing moist paper towels in with the ants will keep them alive.

7. Record basic observations of ant behavior in their new setting, right after introducing them.

8. Have students compare behavioral observations of the ants in their natural habitat versus after being relocated to the plastic containers. 


\section{Appendix 3: Investigating and behavior}

Materials (per group)

Gloves (latex or nitrile)

3-5 Petri dishes

\section{Group Members}

- Recorder

- Manager

- Ant handler(s)

- Clean up expert

Example Procedure

The exact number of ants being used will depend on student hypotheses. Examples of experimental tests are shown in Figure 1. Below is an example procedure testing how "resident" ants will react toward "intruder" ants will react toward "intruder" ants depending on their indentity.

1. Add 5 ants from one colony to a Petri dish. Begin recording time. At least 3 minutes should elapse before the "intruder" ant is added to make sure that the ants are acclimated to their environment. Record "baseline" behavior of ants.

a. Tip: To save time, stagger the acclimation time among several Petri dishes.

2. Select a single ant from the "intruder" colony. While holding the ant with forceps, mark the ant's thorax or abdomen (but avoid getting paint on their heads) with the paint marker. Allow it to dry for $\sim 30$ seconds.

3. Get data recording sheets ready (see Appendix 4) with student-developed experimental designs labeled (or use those provided).

4. Introduce the painted ant to the Petri dish with the 5 other ants.

5. Observe the behavior among ants, stop the interactions if a) heavy fighting is observed (Appendix 4 and Figure 2) or b) one minute has elapsed. Have the students make tickmarks in each field every time each behavior is observed during the minute of observations. If the ants immediately initiate heavy fighting, end the observations and place the intruder ant back in its home colony.

6. Gently place ants that were used for experiments into separate containers and later reintroduce the ants into their respective colonies at the end of the day.

7. Rinse out the Petri dish and dry it. Ask the students why washing is necessary (it is to make sure there aren't any residual smells that can confuse the ants).

Note: Most ant-ant interactions are actually driven by odors and chemical cues. Ants communicate almost exclusively this way, so washing plates is really important!

8. Repeat each interaction type (iteration) 3-5 times

9. Repeat this protocol for any of the experimental designs created by student, or use those outlined in Figure 1 as a rough guide.

10. Add up all of the observations of each behavior for each trial to calculate an average for each behavior type, in each iteration. Compare the behaviors across iterations. It should be clear that ants are highly territorial toward non-nestmates (from both species), while they are less aggressive toward nestmates. 


\section{Appendix 4: Measuring territorial behavior among ant colonies}

Use the scale and images below to rank behavioral changes made by defender ants upon addition of an intruder into their territory. Record data in behavior chart.

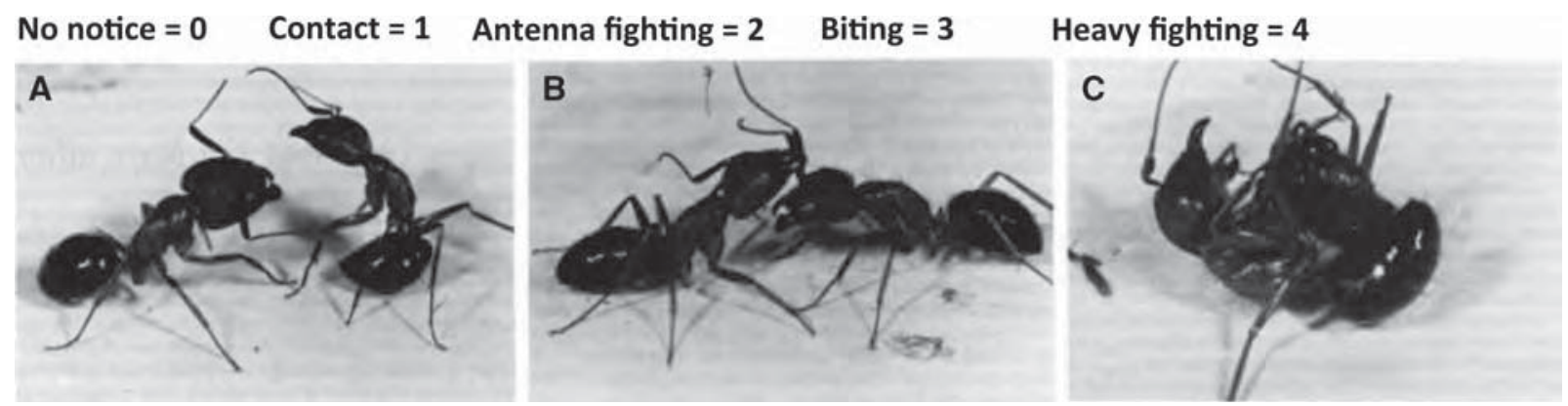

Representative images of aggressive ant behavior including (A) antenna fighting, (B) biting, and (C) heavy fighting. "No notice" and "Contact" can include ants remaining on the opposite side of the dish, or ants in contact with each other but non-intrusively (not shown). At the conclusion of the experiment ask students to answer the discussion questions on a separate piece of paper and save their responses until the following week. Pictures from Holldobler \& Wilson (2009), used with permission.

\section{Discussion Questions}

1. What happened when ants from the same colony were added together? Was there any change when ants from a different colony were added?

2. Does each species of ants act in the same way? Which species was the most aggressive?

3. Does the intruder ant act differently than the group of defender ants? Would you expect that ants would act the same if they weren't given time to acclimate to or "claim" their territory?

4. What are the advantages of territorial/group behavior?

\begin{tabular}{|c|c|c|c|c|c|c|}
\hline \multicolumn{7}{|c|}{ Behavior Chart } \\
\hline Treatment & 0 & 1 & 2 & 3 & 4 & \\
\hline \multirow{3}{*}{$\begin{array}{c}\text { Same Colony } \\
\mathbf{x} \\
\text { Same Species }\end{array}$} & & & & & & Trial 1 \\
\hline & & & & & & Trial 2 \\
\hline & & & & & & Trial 3 \\
\hline \multirow{3}{*}{$\begin{array}{c}\text { Different Colony } \\
\mathbf{x} \\
\text { Same Species }\end{array}$} & & & & & & Trial 1 \\
\hline & & & & & & Trial 2 \\
\hline & & & & & & Trial 3 \\
\hline \multirow{3}{*}{$\begin{array}{c}\text { Different Colony } \\
\mathbf{x} \\
\text { Different Species }\end{array}$} & & & & & & Trial 1 \\
\hline & & & & & & Trial 2 \\
\hline & & & & & & Trial 3 \\
\hline
\end{tabular}

